\title{
Operational Information Requirement Analysis Based on Architecture Modeling
}

\author{
Yinghui Yang \\ Information and Navigation Institute \\ Air Force Engineering University, \\ Shaanxi Xi'an, China \\ e-mail: yangyinghui.good@163.com
}

\section{Jianhua Li}

Information and Navigation Institute Air Force Engineering University,

Shaanxi Xi'an, China

e-mail: KGDLJH@163.com

\author{
Wei Ding \\ Department of Training \\ Air Force Engineering University, \\ Shaanxi Xi'an, China \\ e-mail: Dingwei8011@126.com \\ Mingli Nan \\ Unit 95881 of the PLA \\ Beijing, China \\ e-mail: nanmingli_good@163.com
}

\begin{abstract}
Operational information requirement analysis is the key of sorting out information alternation relationship and implementing effective information flowing. Aiming at the characteristics of operational systems, architecture modeling theory is introduced and applied. Information requirement elements of operational information, nod, activity and phase are defined based on complex network. Four requirement mapping rules between nods and activities, thus Nod $\rightarrow$ Nod, Nod $\rightarrow$ Activity, Activity $\rightarrow$ Nod and Activity $\rightarrow$ Activity, are defined and analyzed. Information requirement models of nod hiberarchy, activity hiberarchy and information alternation are built and the specific modeling flow is also given. Finally, aerial assault phase of aerial offensive campaign (AOC) is taken as an example to validate the method's rationality and feasibility. The results show that this method has provided a new idea and path for operational information requirement analysis. And it is also helpful to enhance operational architecture research's regulation and improve information requirement description' consistency.
\end{abstract}

Keywords-architecture modeling; information requirement; operational activity; mapping rule; model

\section{I .INTRODUCTION}

Architecture modeling is a new operational requirement analysis theory developed in recent years, and has been used successfully in many military requirement analysis domains for its scientific principles, clear process and normative expression etc. [1]. As the projection of operational requirement in information domain, operational information requirement is the demand and expectation of weapon equipment, operational units and command \& control system for combat with the characteristics of dynamic, entirety, and traction etc. It plays crucial guiding and promoting roles in speeding up the supporting capacity building of command information system to research operational information requirement.

In recent years, scholars at home and abroad have made many useful explorations in operational information requirement analysis aspect. The achievements mainly centralize in requirement description concepts, analysis models and normative expression etc. For example, literature [2 defines common concepts and terms of requirement description, and builds concept models in military requirement domain; literature [3] puts forward a requirement analysis development process and its model expression method based on UML for C4ISR system; literature [4] builds a requirement information model and research C4ISR system requirement integration method from syntax, semantics and pragmatics.
But these achievements mainly focus on the concepts and theory frame lacking more refined models to support and combination with operation reality. Therefore, in the following parts, information requirement elements are defined, requirement mapping rules are analyzed and requirement models are built according to architecture modeling theory and method. Finally, aerial assault phase of aerial offensive campaign (AOC) is taken as an example to validate the method's rationality and feasibility.

\section{II .OPERATIONAL INFORMATION REQUIREMENT ELEMENTS AND MAPPING RULE}

As basic follow of scientific requirement analysis, architecture is an organic whole consisting of units, relationships, and principia restricting evolution [5]. Operational information requirement architecture is composed by information requirement elements and mapping rules. Information requirement elements include operational phases, activities, nods and information. Requirement mapping rules include nod $\rightarrow$ nod mapping, nod $\rightarrow$ activity mapping, activity $\rightarrow$ nod mapping and activity $\rightarrow$ activity mapping.

\section{A. Information Requirement Element}

Operation implementation process has typical networked mathematic structure characteristic in the background of network operations. Therefore, complex network theory can be used to define the information requirement elements.

Definition 1: Operational information is defined as the reflection of battlefield objects' characteristic, state and change etc. during operation process. It can be divided into intelligence support information (ISI), operational command information (OCI) and weapon control information (WCI) according to information types. Supposing that there are $I_{0}$ kinds of operational information, and the information can be divided into $X_{0}$ levels in term of difference of operation view particle size. Then operational information set can be noted as $I=\left\{I_{i, j}^{w} \mid i \in\left[1, X_{0}\right], j \in\left[1, I_{0}\right]\right\}$, and the $w$ is value of operation view particle size.

Definition 2: Operational nod is defined as the substantiality producing, gaining, distributing and disposing operational information during operation process. It can be divided into intelligence support nods, command \& control nods and fire striking nods according to nod function. Supposing that there are $N_{0}$ kinds of operational nods, and the nods can be divided into $J_{0}$ levels in term of difference of operation view particle size. Then operational nod set can be noted as $N=\left\{N_{i, j}^{n} \mid i \in\left[1, J_{0}\right], j \in\left[1, N_{0}\right]\right\}$, and the $n$ is value of operation view particle size.

Definition 3: Operational activity is defined as the set of ordered actions for operational nods to accomplish certain specific mission. 
Supposing that there are $A_{0}$ kinds of activities, and the activities can be divided into $H_{0}$ levels in term of difference of operation view particle size. Then activity set can be noted as $A=\left\{A_{i, j}^{a} \mid i \in\left[1, H_{0}\right], j \in\left[1, A_{0}\right]\right\}$, and the $a$ is value of operation view particle size.

Definition 4: Operational phase is defined as the set of ordered actions for operational nods to realize different operation purposes. Supposing that there are $S_{0}$ kinds of operation phases, and the phase set can be noted as $S=\left\{S_{i} \mid i \in\left[1, S_{0}\right]\right\}$. To any phase $S_{i}$, there always is $S_{i}=A_{k, 1} \cup A_{k, 2} \cup \cdots \cup A_{k, j}$, and $k \in\left[1, H_{0}\right], j \in\left[1, A_{0}\right]$.

\section{B. Information Requirement Mapping Rule}

Requirement mapping rules are basic principles of related mappings among information requirement elements during requirement analysis process [6].

- Rule 1: Nod $\rightarrow$ Nod Requirement Mapping

Nod $\rightarrow$ nod requirement mapping is the mapping among operational nods. It determines the information alternated between different nods. The specific rules are as follows:

(1) Supposing the value of operation view particle size is $\pi$;

(2) Select operational information $I_{i, j}^{\pi}$, the producing and consuming nods are $N_{m, p}^{\pi}$ and $N_{m, c}^{\pi}$ separately;

(3) Protract information requirement line from $N_{m, p}^{\pi}$ to $N_{m, c}^{\pi}$, and correspond it with $I_{i, j}^{\pi}$;

(4) Accomplish the nod $\rightarrow$ nod requirement mapping, and note it as $N_{m, p}^{\pi} \stackrel{I_{i, j}^{\pi}}{\longrightarrow} N_{m, c}^{\pi}$.

- Rule 2: Nod $\rightarrow$ Activity Requirement Mapping

Nod $\rightarrow$ activity requirement mapping is the mapping from operational nods to activities. It determines the activities nods participating in. The specific rules are as follows:

(1) Supposing the value of operation view particle size is $\vartheta$;

(2) Select operational nod $N_{i, j}^{\vartheta}$, activities it participating in are $A_{h, l}^{9}, A_{h, 2}^{9}, \cdots, A_{h, n}^{9}$ respectively, which can be expressed uniformly by set $A_{h}^{\vartheta}$ and noted as $A_{h}^{\vartheta}=A_{h, l}^{\vartheta} \cup A_{h, 2}^{\vartheta} \cup \cdots \cup A_{h, n}^{\vartheta}$;

(3) Connect $N_{i, j}^{\vartheta}$ with all the elements in $A_{h}^{\vartheta}$ correspondingly;

(4) Accomplish the nod $\rightarrow$ activity requirement mapping of $N_{i, j}^{9}$, and note it as $N_{i, j}^{\vartheta} \rightarrow A_{h, l}^{\vartheta} \cup A_{h, m}^{\vartheta} \cup \cdots \cup A_{h, n}^{9}$.

- Rule 3: Activity $\rightarrow$ Nod Requirement Mapping

Activity $\rightarrow$ nod requirement mapping is the mapping from operational activities to nods. It determines nods pointed by movable frame mechanism arrows in operational activity IDEF0 diagrams (a structured analysis and design technology expressed by graphical language), and points out the nods involved in certain activities [7]. The specific rules are as follows:

(1) Supposing the value of operation view particle size is $\psi$;

(2) Select operational activity $A_{i, j}^{\psi}$, nods springing it are $N_{t, 1}^{\psi}, N_{t, 2}^{\psi}, \cdots, N_{t, n}^{\psi}$ respectively, which can be expressed uniformly by set $\quad N_{t, r}^{\psi}$ and noted as $N_{t, r}^{\psi}=N_{t, 1}^{\psi} \cup N_{t, 2}^{\psi} \cup \cdots \cup N_{t, n}^{\psi}$;

(3) As the same principle, the control nods set can be noted as $N_{t, z}^{\psi}$, and the output nods set is $N_{t, c}^{\psi}$;

(4) Put $N_{t, r}^{\psi}$ as input nods set of $A_{i, j}^{\psi}$ IDEF0 diagram movable frame, $N_{t, c}^{\psi}$ and $N_{t, z}^{\psi}$ as control and output nods set separately.

(5) Accomplish the activity $\rightarrow$ nod requirement mapping of $A_{i, j}^{\psi}$, and note it as $A_{i, j}^{\psi} \rightarrow N_{t, r}^{\psi} \cup N_{t, z}^{\psi} \cup N_{t, c}^{\psi}$

- Rule 4: Activity $\rightarrow$ Activity Requirement Mapping

Activity $\rightarrow$ activity requirement mapping is the mapping among operational activities. It determines the points of activity IDEF0 diagram movable frame arrows, and clarifies operational information alternated among activities $[7,8]$. The specific rules are as follows:

(1) Supposing the value of operation view particle size is $\theta$;

(2) Select operational information $I_{i, j}^{\theta}$, the producing and consuming activities are $A_{n, p}^{\theta}$ and $A_{n, c}^{\theta} \quad$ separately;
(3) Put $I_{i, j}^{\theta}$ as $A_{n, p}^{\theta}$ IDEF0 diagram movable frame output arrow's data restriction, and $I_{i, j}^{\theta}$ as input arrow (or control arrow)'s.

(4) Accomplish the activity $\rightarrow$ activity requirement mapping, and note it as $A_{n, p}^{\theta} \stackrel{i_{i, j}^{\theta}}{\longrightarrow} A_{n, c}^{\theta}$.

\section{III.Operational Information Requirement Model}

According to mapping rules above, requirement models of nod hiberarchy, activity hiberarchy and information alternation are built respectively based on information requirement elements hierarchical structures. The specific flow is as Fig.1 shows [9].

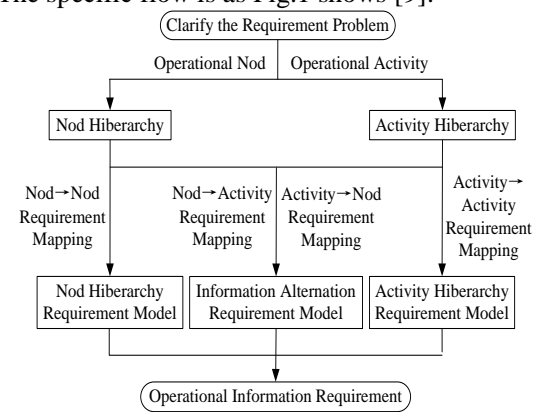

Figure 1. Basic modeling flow of requirement models

Step 1: Decompose operational activities and nods hierarchically according to the difference of operation view particle size;

Step 2: According to nod $\rightarrow$ nod requirement mapping rules, operational information alternated among nods is determined; nod $\rightarrow$ nod requirement mapping and nod hiberarchy requirement model are built combining nods hierarchical structure;

Step 3: According to activity $\rightarrow$ activity requirement mapping rules, operational information alternated among activities is determined; according to nod $\rightarrow$ activity mapping rules, operational activities every nod participating in are determined; according to activity $\rightarrow$ nod requirement mapping rules, operational nods every activity involving are determined; activity $\rightarrow$ activity, nod $\rightarrow$ activity, activity $\rightarrow$ nod requirement mappings and activity hiberarchy requirement model are built combining nods and activities hierarchical structures;

Step 4: Combining operation implement process, information alternation requirement model is built based on the existing mappings.

Step 5: Accomplish operational information requirement analysis based on the three models built above.

\section{A. Model 1: Nod Hiberarchy Requirement Model}

This model reflects the hierarchical information requirement corresponding relationship among nods and can be expressed as two elements function group consisting of operational nods and information, which can be noted as $N M=\Phi(N, I)$ [10]. Supposing the value of operation view particle size is $\alpha$, operational nods can be divided into $\phi$ levels and $\phi \leq J_{0}$. Operational nods and information sets are $N=\left\{N_{m, k}^{\alpha} \mid m \in[1, \phi], k \in\left[1, N_{0}\right]\right\}$ and $I=\left\{I_{i, j}^{\alpha} \mid i \in\left[1, X_{0}\right], j \in\left[1, I_{0}\right]\right\}$ separately; when the value of operation view particle size is $\beta$, operational nods can be divided as $\varphi$ levels and $\beta<\alpha, \phi<\varphi \leq J_{0}$. Operational nods and information sets are $N=\left\{N_{e, s}^{\beta} \mid e \in[1, \varphi], s \in\left[1, N_{0}\right]\right\} \quad$ and $I=\left\{I_{g, h}^{\beta} \mid g \in\left[1, X_{0}\right], h \in\left[1, I_{0}\right]\right\} \quad$ separately, as Fig.2 shows.

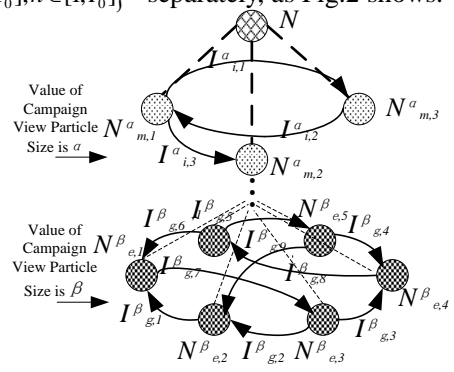

Figure 2. Nod hiberarchy requirement model

B. Model 2: Activity Hiberarchy Requirement Model 
This model reflects the hierarchical operational activities, and can be expressed as three elements function group consisting of operational activities, information and nods, which can be noted as $H M=\Theta(A, I, N)$.Supposing the value of operation view particle size is $\chi$, operational activities can be divided into $\varepsilon$ levels and $\varepsilon \leq H_{0}$. Operational activities, information and activities sets are $A=\left\{A_{n, t}^{\chi} \mid n \in[1, \varepsilon], t \in\left[1, A_{0}\right]\right\} \quad, \quad I=\left\{I_{p, q}^{\chi} \mid p \in\left[1, X_{0}\right], q \in\left[1, I_{0}\right]\right\} \quad$ and $N=\left\{N_{f, l}^{\chi} \mid f \in\left[1, H_{0}\right], l \in\left[1, N_{0}\right]\right\}$ separately; when the value of operation view particle size is $\delta$, operational activities can be divided into $\gamma$ levels and $\delta<\chi, \varepsilon<\gamma \leq H_{0}$. Operational activities, information and activities sets are $A=\left\{A_{b, c}^{\delta} \mid b \in[1, \gamma], c \in\left[1, A_{0}\right]\right\}, I=\left\{I_{w, v}^{\delta} \mid w \in\left[1, X_{0}\right], v \in\left[1, I_{0}\right]\right\}$ and $N=\left\{N_{z, x}^{\delta} \mid z \in\left[1, H_{0}\right], x \in\left[1, N_{0}\right]\right\}$ separately, as Fig.3 shows

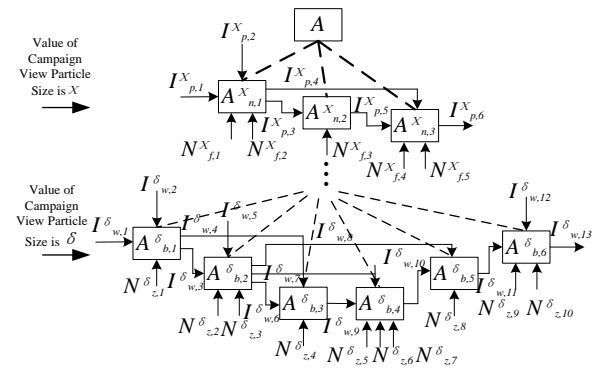

Figure 3. Activity hiberarchy requirement model

\section{Model 3: Information Alternation Requirement Model}

This model reflects the information alternation relationship among nods, and can be expressed as three elements function group consisting of operational information, activities and nods, which can be noted as $I M=\Psi(I, N, A)[4]$. Supposing the value of operation view particle size is $\eta$, select operational information $I_{i, j}^{\eta}$, the producing and consuming nod sets are $N_{m, p}^{\eta}$ and $N_{m, c}^{\eta}$ separately, the producing and consuming activity sets are $A_{m, p}^{\eta}$ and $A_{m, c}^{\eta} \quad$ separately. Then the information alternation requirement model can be noted as $\left\{N_{m, p}^{\eta} \mid A_{m, p}^{\eta}\right\} \stackrel{I_{i, j}^{\eta},}{\longrightarrow}\left\{N_{m, c}^{\eta} \mid A_{m, c}^{\eta}\right\}$. As the same principle, when the value of operation view particle size is $\omega(\omega<\eta)$, this model can be noted as $\left\{N_{m, p}^{\omega} \mid A_{m, p}^{\omega}\right\} \stackrel{I_{i, j}^{\omega}}{\longrightarrow}\left\{N_{m, c}^{\omega} \cup A_{m, c}^{\omega}\right\}$.

\section{IV.EXAMPLE}

In the condition of network operations, take aerial assault phase of AOC as example, information requirement can be analyzed referring to literature [7, 10]. Applying this method, the information requirement analysis frame can be built as Fig. 4 shows.

\begin{tabular}{|c|c|c|c|c|c|}
\hline \multirow{2}{*}{ \1 } & \multicolumn{5}{|c|}{ Information Requirement of Aerial Assault Phase } \\
\hline & \multicolumn{5}{|c|}{4} \\
\hline \multirow[t]{2}{*}{$\begin{array}{c}\text { Requirement } \\
\text { Model }\end{array}$} & $\begin{array}{r}\text { Nod Hibera } \\
\text { Requirement }\end{array}$ & $\begin{array}{l}\text { chy } \\
\text { Model }\end{array}$ & $\begin{array}{l}\text { Inform: } \\
\text { Requ }\end{array}$ & $\begin{array}{l}\text { tion Alternation } \\
\text { rement Model }\end{array}$ & $\begin{array}{l}\text { Activity Hiberarchy } \\
\text { Requirement Model }\end{array}$ \\
\hline & \multicolumn{5}{|c|}{37} \\
\hline $\begin{array}{c}\text { Mapping } \\
\text { Rule }\end{array}$ & \begin{tabular}{|l} 
Nod $\rightarrow$ Nod \\
Requirement \\
Mapping \\
\end{tabular} & \multicolumn{2}{|c|}{$\begin{array}{c}\text { Nod } \rightarrow \text { Activity } \\
\text { Requirement } \\
\text { Mapping }\end{array}$} & $\begin{array}{c}\text { Activity } \rightarrow \text { Nod } \\
\text { Requirement } \\
\text { Mapping }\end{array}$ & \begin{tabular}{|c} 
Activity $\rightarrow$ Activity \\
Requirement \\
Mapping
\end{tabular} \\
\hline & \multicolumn{5}{|c|}{37} \\
\hline $\begin{array}{c}\text { Requirement } \\
\text { Element }\end{array}$ & $\begin{array}{l}\text { Operati } \\
\text { Activ }\end{array}$ & & & $\begin{array}{l}\text { erational } \\
\text { Nod }\end{array}$ & $\begin{array}{l}\text { Operational } \\
\text { Information }\end{array}$ \\
\hline
\end{tabular}

Figure 4. Information requirement analysis frame

\section{A. Aerial Assault Phase Analysis}

It is crucial phase for AOC that assaulting targets at land or sea from air. It mainly includes intelligence reconnaissance, electronic jamming and assaulting taches. In intelligence reconnaissance tache, through applying multi- reconnaissance force including radar, electronic warfare and technical reconnaissance synthetically, accurate position, shape characteristics, quantity scale, air defense and self-protection ability of enemy important targets are reconnoitered focused. These targets include air force bases, combat aircrafts, air defense weapons, especially large-scale radars, missile and antiaircraft gun positions etc. In electronic jamming tache, enemy electronic equipment is mainly suppressed, jammed and deceived. Important radar stations, command $\&$ control system, electromagnetism targets etc. are suffered anti-radiation attack. These manoeuvers will form and keep a strong jamming area. As the result, make enemy radars will be perplexed and the performance of command \& control system and anti-air weapon system reduced. In assaulting tache, main enemy targets and crucial parts are attacked centralized under region command post (RCP)'s command and coordination, especially air defense system and aerial counterattack operational system. After first assaulting, multi-reconnaissance methods, such as satellite, aviation and ground reconnaissance, are taken to find out assaulting effect and enemy troops deploy change etc. Then command posts will modify their later assaulting targets and methods, and select some important targets destroyed in different extend as preferential continuous attack objects to destroyed drastically or suppressed chronically.

According to the combat process above, operational activities can be divided into intelligence reconnaissance activity (IRA), electronic confronting activity (EJA) and assaulting activity (AA). Operational nods can be divided into intelligence support nod (ISN), including radar troop (RT), electronic confronting corps (ECC), intelligence center (IC) and warning satellite (WS), command \&control nod (CCN), including general command post (GCP) and region command post (RCP), and fire striking nod (FSN) - aviation division (AD). Operational information can be divided into ISI, OCI and WCI.

\section{B. Nod Hiberarchy Requirement Model}

According to the difference of operation view particle size, AD can be divided hierarchically into division command post (DCP), warning \& command craft (WCC), jamming formation (JF), suppressing formation (SF), assaulting formation (AF) and covering formation (CF). RT can be divided hierarchically into troop command post (TCP), radar battalion (RB) a, b and c.

According to requirement mapping rule1(nod $\rightarrow$ nod requirement mapping rule), twenty three FSN interior mappings, fourteen ISN interior mappings, two CCN interior mappings and twenty one cross set mappings are built, which sums up to sixty nod $\rightarrow$ nod mappings. The specific are as follows: GCP transfers OCI to RCP, AD and IC; RCP transfers OCI to GCP, AD, RT and IC, and also transfers OCI and WCI to ECC as well as WS; RD, ECC and WS transfers ISI to IC and AD; IC transfers ISI to GCP, RCP and AD; AD transfers ISI to RT, ECC, IC and WS, and also transfers OCI to GCP and RCP; TCP transfers OCI and WCI to RB a, b and c; RB a, b and c transfers ISI to TCP; DCP transfers OCI, ISI and WCI to WCC; WCC transfers ISI to DCP, and also transfers OCI, ISI and WCI to JF, SF, AF and SF; JF, SF, AF and SF transfers ISI to WCC. According to the analysis above, nod hiberarchy requirement model can be built as Fig. 5 shows.
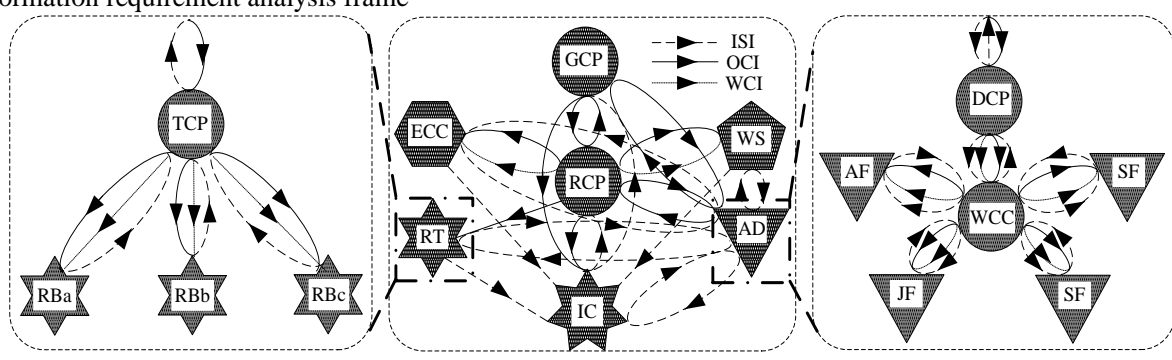

Figure 5. Nod hiberarchy requirement model

\section{Activity Hiberarchy Requirement Model}

According to the difference of operation view particle size, IRA can be divided hierarchically into warning detecting (WD), identification of friend (IFF) and information amalgamation (IA); ECA can be divided hierarchically into electronic reconnaissance 
(ER), electronic jamming (EJ) and fire destroy (FD); Assaulting activity (AA) can be divided hierarchically into standoff assaulting (SA) and precise assaulting (PA).

According to requirement mapping rule4(activity $\rightarrow$ activity requirement mapping rule), two IRA interior mappings, two ECA interior mappings, one AA interior mapping and three cross set mappings are built, which sums up to eight activity $\rightarrow$ activity mappings[11]. The specific are as follows: IRA transfers ISI to ECA and AA; ECA transfers ISI to AA. WD transfers ISI to IFF; IFF transfers ISI to IA; ER transfers ISI to EJ; EJ transfers ISI to FD; SA transfers ISI to PA.
According to requirement mapping rule 2 and 3 (nod $\rightarrow$ activity and activity $\rightarrow$ nod requirement mapping rules), sixteen nod $\rightarrow$ activity mappings and eleven activity $\rightarrow$ nod mapping are built, which sums up to twenty seven mappings. The specific are as follows: RT, ECC, IC and WS implement IRA; ECC and AD implement ECA; AD implements AA; RB a, b, c, ECC and WS implement WD; RB a, b and c implement IFF; IC implement IA; ECC, WCC, JF and CF implement ER; WCC, JF and CF implement EJ; WCC, JF, SF, AF and $\mathrm{CF}$ implement FD; WCC, JF, SF, AF and CF implement SA and PA. According to the analysis above, activity hiberarchy requirement model can be built as Fig.6 shows.

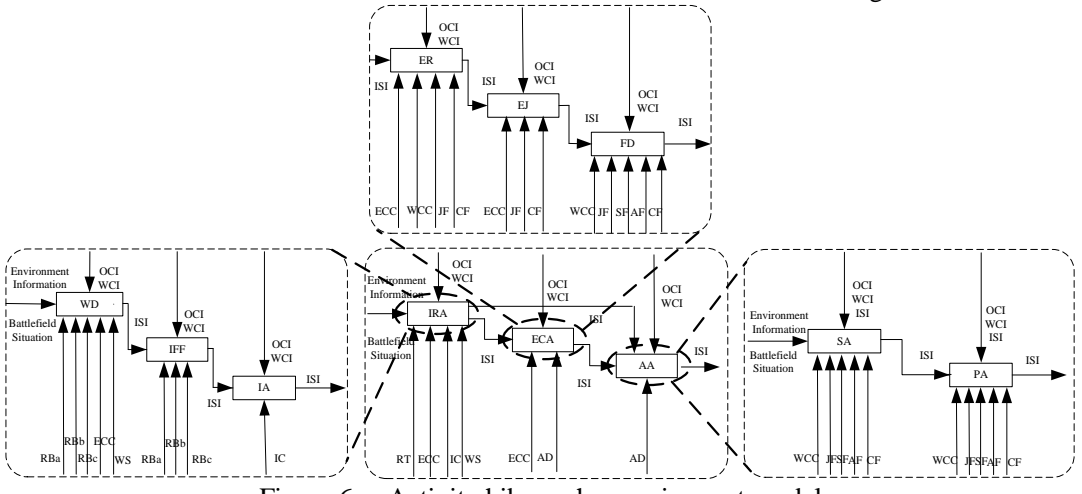

Figure 6. Activity hiberarchy requirement model

\section{Information Alternation Requirement Model}

According to four requirement mappings and combining aerial assault phase implement process, information alternation requirement

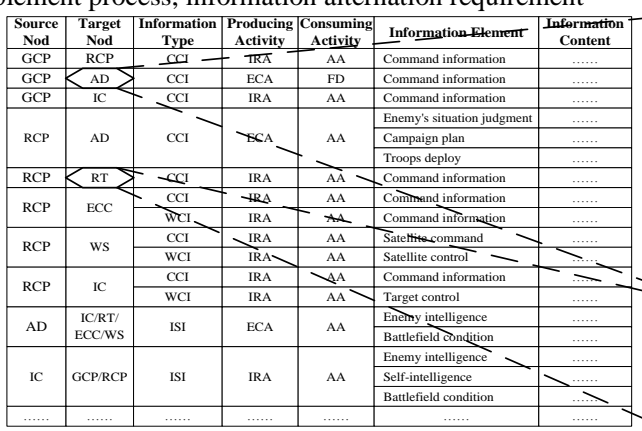

Figure 7. Information

The requirement analysis structure and models built are helpful to clarify requirement analysis idea, subdivide analysis process and stand out information requirement elements' status and effect in requirement analysis process. It makes requirement expression more intuitionistic, normative and clear and also validates the method's rationality and feasibility well.

\section{V.CONCLUSION}

It is inheritance and development of existing operational requirement analysis achievements that analyzing information requirement based on architecture modeling theory. In this paper, information requirement elements are defined, requirements mapping rules are researched, and requirements models are built. A new method for information requirement analysis is provided, which is helpful to enhance requirement analysis criterion and consistency, as well as requirement expression veracity. Also, it offers theory support and measure guarantee for researching requirement analysis's normative pattern and developing supporting software platform.

\section{VI.ACKNOWLEDGMENT}

Project supported by the National Nature Science Foundation of China (No. 61174162).

* Corresponding author: Yinghui Yang

Email: yangyinghui.good@163.com

\section{REFERENCE}

[1] DoD Acrhitecture Framework Working Group. DoD architecture model can be built as Fig.7 shows [12].

\begin{tabular}{|c|c|c|c|c|c|c|}
\hline $\begin{array}{c}\begin{array}{c}\text { Source } \\
\text { Nod }\end{array} \\
\end{array}$ & $\begin{array}{c}\begin{array}{c}\text { Target } \\
\text { Nod }\end{array} \\
\end{array}$ & $\begin{array}{c}\text { Information } \\
\text { Type }\end{array}$ & \begin{tabular}{|c|}
$\begin{array}{c}\text { Producing } \\
\text { Activity }\end{array}$ \\
\end{tabular} & \begin{tabular}{|c}
$\begin{array}{c}\text { Consuming } \\
\text { Activity }\end{array}$ \\
\end{tabular} & Information Element & $\begin{array}{c}\text { Information } \\
\text { Content }\end{array}$ \\
\hline \multirow{3}{*}{ DCP } & \multirow{3}{*}{ wCC } & \multirow[t]{2}{*}{ ISI } & \multirow[t]{2}{*}{ ERA } & & \begin{tabular}{|l|} 
Enemy intelligence \\
Battlefield condition \\
\end{tabular} & $\ldots \ldots$ \\
\hline & & & & & Enemy's situation judgment & $\ldots \ldots$ \\
\hline & & $\mathrm{WCl}$ & LIA & HA & Campaign plan & $\ldots \ldots$. \\
\hline \multirow{2}{*}{ wcC } & \multirow[b]{2}{*}{ DCP } & \multirow[b]{2}{*}{ ISI } & \multirow[b]{2}{*}{ ERA } & \multirow[b]{2}{*}{${ }^{P}$} & $\begin{array}{l}\text { Control order } \\
\end{array}$ & $\ldots \ldots$ \\
\hline & & & & & Battlefield condition & $\ldots \ldots$ \\
\hline wcC & $\mathrm{JF}$ & ISI & ERA & $\mathrm{PA}^{\mathrm{A}}$ & Enemy intelligence & 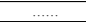 \\
\hline \multirow{3}{*}{ wCC } & \multirow{3}{*}{$\mathrm{JF}$} & $\mathrm{CCI}$ & ERA & $\mathrm{PA}$ & $\begin{array}{l}\text { Batlefieled conditition } \\
\text { Command order }\end{array}$ & \\
\hline & & $\mathrm{wCI}$ & ERA & $\mathrm{PA}_{\mathrm{A}}$ & $\begin{array}{l}\text { Control order } \\
\end{array}$ & \\
\hline & & & & $\ldots \ldots$ & ....... & $\ldots$ \\
\hline $\begin{array}{c}\text { Source } \\
\text { Nod }\end{array}$ & $\begin{array}{c}\text { Target } \\
\text { Nod }\end{array}$ & $\begin{array}{c}\text { Information } \\
\text { TYpe }\end{array}$ & $\begin{array}{c}\begin{array}{c}\text { Producing } \\
\text { Attivity }\end{array} \\
\end{array}$ & $\begin{array}{c}\text { Consuming } \\
\text { Atfivity }\end{array}$ & Information Element & $\begin{array}{c}\text { Information } \\
\text { Content }\end{array}$ \\
\hline \multirow{3}{*}{ TCP } & \multirow{3}{*}{$\mathrm{RB} \times$} & \multirow{2}{*}{$\mathrm{CCl}$} & & & Command order & \\
\hline & & & & & Target surveillance & \\
\hline & & wCI & WD & IFF & Control order & (. \\
\hline $\mathrm{RB} \times$ & TCP & ISI & WD & IFF & Radar intelligence & 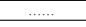 \\
\hline
\end{tabular}

requirement model

framework version 2.0 [R]. U.S. : Department of defense, 2009.

[2] Yu Bin, Duan Cai-yu, Rao De-hu. A conceptual model for describing $\mathrm{C}^{4} \mathrm{ISR}$ military requirements [J]. Journal of National University of Defense Technology, 2008,30(02):112-117.

[3] Chen Hong-hui, Fu Guang-sheng, Rui Hong. Research of concordance development of $\mathrm{C}^{4} \mathrm{ISR}$ system requirements [J]. Fire Control \& Command Control, 2009,34(11):118-121.

[4] Lv Xiang, Luo Xue-shan, Liu Jun-xian. Research on integration method of $\mathrm{C}^{4} \mathrm{ISR}$ system military requirements based on information model $[\mathrm{J}]$, Fire Control \& Command Control, 2011,35(04):68-72.

[5] Xie Wen-cai, Luo Xue-shan, Luo Ai-min. Meta-model based modeling of military information system architecture[J]. Journal of National University of Defense Technology, 2012,34(01):82-87.

[6] Berry, Daniel M. Requirements engineering: foundation for software quality[C].17th International Working Conference on Requirement Engineering, 2011.

[7] Otto H. Heuckeroth, Sam E. Middlebrooks. An investigation of combat vehicle ventilation requirements[R]. U.S.: Army Research Laboratory, 2011.

[8] Duan Cai-yu, Yu Bin, Zhang Wei-ming, Rao De-hu. C ${ }^{4}$ ISR requirements model and integrative description [J]. Journal of System Engineering, 2008,23(05):519-525.

[9] Michael G.Alexander. Requirement assurance: a verification process[R]. Langley Research Center, Hampton, Virginia, 2011.

[10] Dhirendra Pandey, Ugrasen Suman, A. K. Ramani. An approach to information requirement engineering [C]. 2011 International Conference on Information Science and Applications, 2011.

[11] Ian Sommerville, Russell Lock, Tim Storer, etc. Deriving 
information requirements from responsibility models [J]. Lecture Notes in Computer Science, 2009, 5565 (1): 515-529.

[12] Hamed Farahani Manesh , Dirk Schaefer. Information requirements analysis for holonic manufacturing systems in a virtual environment $[\mathrm{J}]$. The International Journal of Advance Manufacturing Technology, 2011, 53 (1): 385-398. 